\title{
Antibiotic susceptibility and resistance testing: An overview
}

Fiona Smaill MB ChB

\begin{abstract}
F Smaill. Antibiotic susceptibility and resistance testing: An overview. Can J Gastroenterol 2000;14(10):871-875. The results of in vitro antibiotic susceptibility testing can predict the clinical response to treatment and guide the selection of antibiotics. The minimum inhibitory concentration (MIC) of an organism is the lowest concentration of an antibiotic that will inhibit its growth. Bacteria are classified as sensitive, intermediate or resistant based on breakpoint MIC values that are arbitrarily defined and reflect the achievable levels of the antibiotic, the distribution of MICs for the organism and their correlation with clinical outcome. Broth dilution, agar dilution and gradient diffusion (the 'E test'), where twofold serial dilutions of antibiotic are incorporated into tubes of broth, agar plates or on a paper strip, respectively, are different methods to measure the MIC of an organism. The disk diffusion method defines an organism as sensitive or resistant based on the extent of its growth around an antibiotic-containing disk. MIC values are influenced by several laboratory factors. To ensure reproducible results, the laboratory must closely follow methods developed by the National Committee for Clinical Laboratory Standards, which defines standard growth media, incubation temperature and environment, the inoculum and quality control parameters.
\end{abstract}

Key Words: Antibiotic; E test; Disk diffusion test; Miminum inhibitory concentration

\section{Sensibilité aux antibiotiques et tests de résistance : Vue d'ensemble}

RÉSUMÉ : Les résultats des épreuves in vitro de sensibilité aux antibiotiques permettent de prédire la réponse clinique au traitement et d'orienter le choix d'un antibiotique. La concentration minimum inhibitrice (CMI) d'un organisme est la concentration la plus faible d'un antibiotique capable d'en inhiber la croissance. Les bactéries sont dites sensibles, à résistance intermédiaire ou résistantes, selon des valeurs seuils de CMI qui sont arbitrairement définies et reflètent les concentrations d'antibiotique atteignables. Les différentes méthodes pour mesurer la CMI d'un organisme sont : distribution des CMI de l'agent pathogène et leur corrélation avec l'issue clinique, dilution en bouillon de culture, sur gélose et diffusion du gradient (test $\mathrm{E}$ ) où des dilutions doubles d'antibiotiques en série sont respectivement incorporées à des éprouvettes contenant un bouillon de culture, à des plaques de gélose ou à des bandelettes de papier. La méthode de diffusion sur gélose permet de déterminer si un organisme est sensible ou résistant selon son degré de croissance autour du disque renfermant l'antibiotique. Les valeurs de CMI subissent l'influence de plusieurs facteurs liés aux pratiques de laboratoire. Pour assurer des résultats reproductibles, le laboratoire doit suivre à la lettre les méthodes mises au point par le National Committee for Clinical Laboratory Standards qui fixe les paramètres officiels des milieux de croissance standard, de la température et du milieu d'incubation, de l'inoculum et du contrôle de la qualité.
$\mathrm{I}^{\mathrm{n}}$ n 1928, Alexander Fleming observed that staphylococcal colonies growing adjacent to a mold contaminating a culture plate were undergoing lysis and correctly concluded that the mold, later identified as a strain of Penicillium, was producing some diffusible product capable of inhibiting the growth of the bacteria. Within a few years of the introduction of penicillin, however, strains of Staphylococcus aureus resistant to penicillin were recognized, and susceptibility testing of bacteria quickly became a practical necessity. Only a few bacteria have maintained a predictable susceptibility

Faculty of Health Sciences, McMaster University, Hamilton, Ontario

Correspondence and reprints: Dr Fiona Smaill, Room 2N29, McMaster University Medical Centre, 1200 Main Street West, Hamilton, Ontario

L8N 325. Telephone 905-521-9800 ext 76307, fax 905-521-5099, e-mail smaill@mcmaster.ca

Received for publication May 15, 2000. Accepted June 13, 2000 


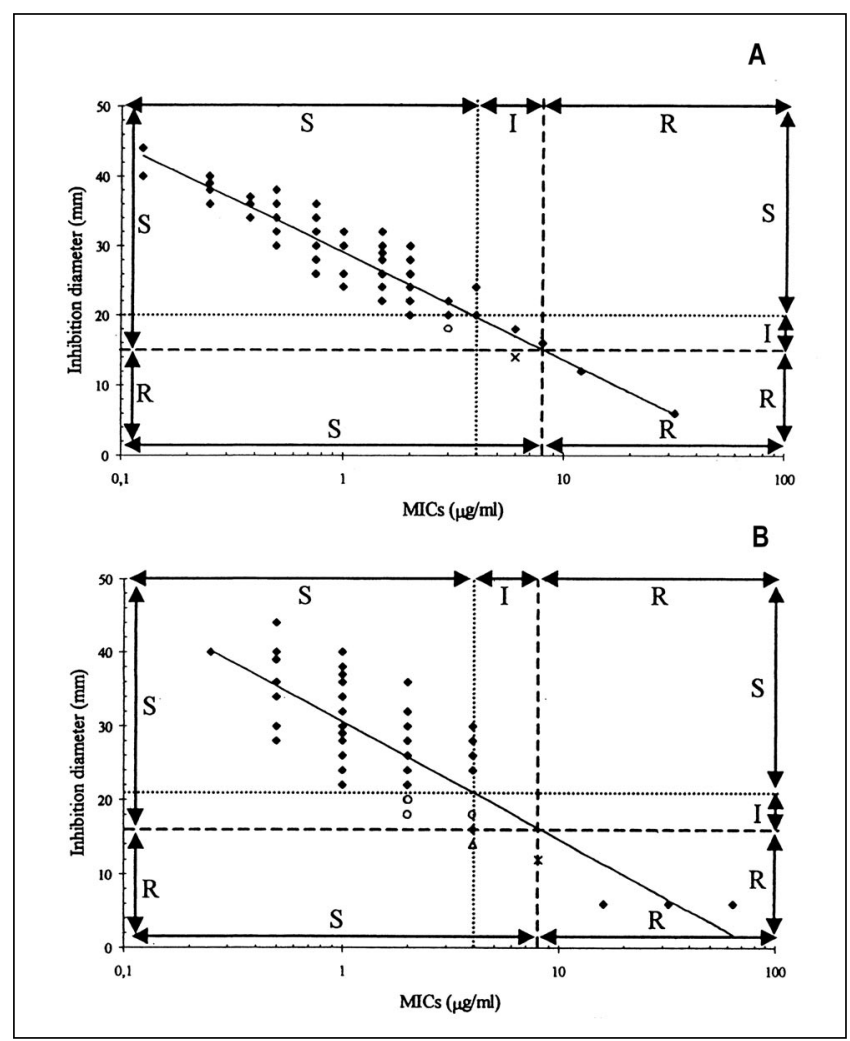

Figure 1) Regression analysis, plotting the zone of inhibition by disk diffusion against the log minimum inhibitory concentration defined by E-test (A) and agar dilution (B) for strains of Helicobacter pylori against metronidazole. I Intermediate; R Resistant; S Susceptible. Reproduced with permission from reference 8

pattern. Virtually all strains of group A streptococcus remain sensitive to penicillin, but for the management of most bacterial infections, clinicians depend on the laboratory to provide accurate and timely susceptibility results to guide initial and subsequent antibiotic decisions.

Antibiotic resistance has become a major public health threat. Nosocomial infections with methicillin-resistant $S$ aureus and vancomycin-resistant enterococcus are common in many Canadian hospitals, and rates of resistance to penicillin in Streptococcus pneumoniae of $20 \%$ or more are challenging the empirical management of respiratory tract infections in the community. Bacterial resistance parallels antibiotic use. For example, the increased use of ciprofloxacin has been linked to increasing rates of quinolone resistance in strains of pneumococci (1). In the absence of new drugs, appropriate antibiotic prescribing is the only effective weapon against the threat of resistance. In Finland, where erythromycin resistance in group A streptococci was $16.5 \%$, a reduction in the use of macrolides was associated with a significant decline in the rate of resistance (2).

The aim of antimicrobial susceptibility testing is simple to predict the clinical outcome of treatment. An organism classified as susceptible should respond to the antimicrobial agent; if the organism is resistant there is a high probability of failure (3). Strains that are classified as intermediate fall somewhere in between; higher doses in certain circum- stances may be associated with a favourable outcome. The factors that determine the outcome of antibiotic treatment of infection are, however, complex and not adequately measured by the in vitro tests performed in the laboratory. Low concentrations of antibiotics can affect bacterial growth (4), and bacterial growth may continue to be suppressed after a brief exposure to certain antibiotics (the 'postantibiotic effect') (5). Neither of these activities, however, can be easily incorporated into routine laboratory susceptibility testing procedures.

The goal of the laboratory is to provide standardized in vitro tests that can be reproduced from day to day and from laboratory to laboratory. Only by using standard growth media, incubating in a defined temperature and environment, and using a standard inoculum can the reproducibility of results be assured. For all antibiotic susceptibility testing performed in the laboratory, control organisms with known susceptibility are tested. If they fail to give the expected result, the results of any tests run concurrently must be disregarded. If there are errors, corrective measures must be implemented and the expected result obtained before patient isolates can be tested and results reported. Quality control is an integral part of any laboratory procedure. In North America, the National Committee for Clinical Laboratory Standards (NCCLS) develops standards to promote accurate susceptibility testing, providing reference methods and quality control parameters, and establishing interpretative criteria. Tentative guidelines for the susceptibility testing of Helicobacter pylori have recently been published (6).

It is important to recognize that the laboratory brings the 'bug and drug' together artificially in a setting outside of the host environment. An agar plate containing MuellerHinton agar and aged sheep blood that supports the growth of $\mathrm{H}$ pylori is quite different from conditions within the gastric mucosa. The continuous exposure of a relatively small number of organisms to constant levels of antibiotic that occurs with in vitro testing differs considerably from the clinical setting in which large numbers of organisms are exposed to fluctuating levels of drug. There have been attempts to use different models for antimicrobial susceptibility testing of $H$ pylori that more closely approximate the clinical milieu, but none is suitable for routine use (7).

\section{DETERMINING THE MINIMUM INHIBITORY CONCENTRATION}

The goal of laboratory testing is to quantify the lowest concentration of an antibiotic that inhibits the visible growth of the microbe - the minimum inhibitory concentration (MIC). For broth dilution tests, serial twofold dilutions of an antimicrobial are incorporated into broth-containing tubes that are then inoculated with a standard number of organisms. After overnight incubation, the tubes are inspected for visible growth. The MIC is the lowest concentration of the drug that prevents visible growth. The $\mathrm{MIC}_{50}$ and the $\mathrm{MIC}_{90}$ are the concentrations of antibiotic that inhibit $50 \%$ and $90 \%$, respectively, of strains tested of a particular bacterial species. Describing the range and distribution of MICs 
TABLE 1

Suggested modifications of standard methods for susceptibility testing of Helicobacter pylori

\begin{tabular}{|c|c|c|c|}
\hline Method* & Medium & Incubation & Comments \\
\hline Agar dilution & $\begin{array}{l}\text { MHA plus aged (for two weeks or more) } \\
\text { sheep blood ( } 5 \% \text { volume/volume) }\end{array}$ & $\begin{array}{c}35^{\circ} \mathrm{C} \text {; three days; microaerobic atmosphere } \\
\text { suitable for campylobacters }\end{array}$ & $\begin{array}{l}\text { Gas system-generated } \\
\text { microaerobic atmosphere }\end{array}$ \\
\hline
\end{tabular}

provides further information on the activity of antibiotics against different bacterial species.

Besides broth dilution, there are other ways to determine the MIC. Using an agar dilution method, dilutions of antibiotic are incorporated into agar. For the gradient diffusion method, a concentration gradient of antibiotic is incorporated into a strip (the 'E-test'; AB Biodisk, Sweden). For disk diffusion, the amount of inhibition of growth around an antibiotic disk is correlated with the MIC of the organism. There is no agreement as to whether any one of these methods more closely approximates the living human milieu. Whatever method is selected, it must support the growth of the organism. The rapid, automated antibiotic susceptibility systems, eg, Vitek (bioMérieux, USA) and Microscan (Dade Behring, USA), used for most of the routine organisms isolated in the laboratory, do not support the growth of H pylori, which require a microaerophilic atmosphere.

While agar dilution, broth dilution and antibiotic gradient testing methods provide an actual MIC, the disk diffusion method defines an organism as either resistant or susceptible based on zone diameters that have been previously correlated with MIC values. A regression analysis is performed, plotting the zone size against the MIC, and breakpoint zone diameters are chosen that correspond to the MICs in the sensitive and resistant ranges (Figure 1).

In any comparison of methods, rates for very major, major and minor errors should be expressed. A very major error occurs when a resistant strain is called sensitive; a major error occurs when a sensitive strain is called resistant. Minor errors occur when there is a discrepancy between methods and a strain that is found to be intermediate by one method is found to be either sensitive or resistant by another. In a recent study that compared agar dilution, disk dilution and E-tests for $\mathrm{H}$ pylori, no very major errors were reported, and only $1 \%$ major errors and $7 \%$ minor errors when disk diffusion was compared with agar dilution (8). These error rates are within the acceptable range.

MIC values are influenced by a number of factors, including the composition of the media, the size of the inoculum, the duration of incubation and the presence of resistant subpopulations. Dore et al (9) demonstrated that there can be considerable variability in metronidazole susceptibility in $\mathrm{H}$ pylori when several colonies were tested individually compared with testing of pooled colonies. Minor changes in $\mathrm{pH}$ can affect the MIC. Studies have shown that, while clarithromycin is bactericidal at $\mathrm{pHs}$ of 7.0 to 7.4 , it is bacteristatic at $\mathrm{pH} 6.5$ (10). The MIC for ampicillin is higher at
TABLE 2

Variability in breakpoints used to define resistance to metronidazole and clarithromycin in Helicobacter pylori

\begin{tabular}{lcc} 
Antibiotic & MIC breakpoint & Geographic origin of strains \\
\hline Metronidazole & $\geq 4$ & Peru \\
& $>4$ & Canada/Europe \\
& $\geq 64$ & United States \\
& $\geq 8$ & Norway \\
& $\geq 16$ & Canada joint study \\
& $>8$ & Montreal, Quebec \\
& $>8$ & Halifax, Nova Scotia \\
& $>32$ & Belgium \\
& $>32$ & Italy \\
& $>32$ & Netherlands \\
& $\geq 0.125$ & Peru \\
$\geq 2$ & Canada/Europe \\
& $\geq 4$ & Canada joint study \\
& $>2$ & Montreal, Quebec \\
& $>2$ & Halifax, Nova Scotia \\
& $>8$ & Italy \\
$\geq 2$ & United States \\
\hline
\end{tabular}

MIC Minimum inhibitory concentration. Reproduced with permission from reference 13

lower $\mathrm{pHs}$, while for metronidazole, the MIC does not appear to change significantly with changes in $\mathrm{pH}$. Supplements added to the media can change the percentage of resistant strains; in one study where the media was supplemented with haemin (X factor) and menadione, the rate of apparent resistance to metronidazole dropped from $80 \%$ to $39 \%$ (11). Both the inoculum and the incubation time are also associated with differences (12). These have been standardized in the new proposed NCCLS guidelines (Table 1) (6).

\section{ESTABLISHING THE BREAKPOINTS}

The ultimate goal of antimicrobial susceptibility testing is to predict the clinical outcome by classifying a bacterial strain as susceptible, intermediate or resistant on the basis of established breakpoints based on the MIC. Breakpoints are derived by a consensus mechanism that involves the practical consideration of clinicians, microbiologists and pharmacologists. As such, they are largely arbitrary. Different groups have defined different breakpoints for resistance in $H$ pylori (Table 2) (13). A breakpoint for an antibiotic is usually se- 
lected as the therapeutic concentration in blood that can be readily achieved with usual dosing regimens, but this is not always easy to determine. For some antibiotics, eg, the penicillins, the amount of time that the antibiotic level is above the MIC is associated with successful therapy; for other drugs with concentration-dependent action, such as the aminoglycosides and quinolones, the determinant of killing is some measure of the area under the concentration time curve divided by the MIC. For some antibiotics with mostly intracellular activity, serum levels may be misleading. Breakpoints can sometimes be established by examining the MIC distributions of isolates, but for metronidazole, there is no clear cutoff between resistant and sensitive strains of $H$ pylori. For clarithromycin, however, strains appear to fall into resistant and sensitive populations, making a breakpoint easier to define.

Different countries have defined different breakpoints to define resistance. While this difference may be related to different dosages or ways of administering antibiotics, some countries may be more or less conservative in assessing susceptibility. Some countries may use different methods, eg, size of the inoculum and media, which can affect the MIC and breakpoints. Comparing resistance rates among countries if different methods have been used for susceptibility testing can be confusing.

It might be assumed that a procedure used as extensively as susceptibility testing would have been shown to correlate closely with clinical outcome. Unfortunately, there is a paucity of studies that have critically evaluated the effectiveness of antibiotic therapy with results of in vitro susceptibility tests (14). During clinical trials of new agents, an attempt is made to correlate the response rates for organisms with their MIC, but rarely are there adequate data on clinical and bacteriological responses to use this method solely for determining the breakpoint. Data are accumulating to show that the success of eradication therapy for $\mathrm{H}$ pylori is significantly limited in the presence of drug resistance, and resistance to antibiotics is considered the primary reason for failure of eradication therapies for $\mathrm{H}$ pylori (15).

For treatment of $\mathrm{H}$ pylori, a combination of drugs is given,

\section{REFERENCES}

1. Chen DK, McGeer A, de Azavedo JC, Low DE. Decreased susceptibility of Streptococcus pneumoniae to fluoroquinolones in Canada. Canadian Bacterial Surveillance Network. N Engl J Med 1999;341:233-9.

2. Seppala H, Klaukka T, Vuopio-Varkila J, et al. The effect of changes in the consumption of macrolide antibiotics on erythromycin resistance in group A streptococci in Finland. Finnish Study Group for Antimicrobial Resistance. N Engl J Med 1997;337:441-6.

3. Turnidge JD, Jorgensen JH. Antimicrobial susceptibility testing: General considerations. In: Murray PR, Baron EJ, Pfaller MA, Tenover FC, Yolken RH, eds. Manual of Clinical Microbiology, 7th edn. Washington: American Society of Microbiology, 1999:1469-73.

4. Gemmell CG, Lorian V. Effects of low concentrations of antibiotics on bacterial ultrastructure, virulence and susceptibility to immunodefenses: Clinical significance. In: Lorain V, ed. Antibiotics in Laboratory Medicine, 4th edn. Baltimore: Williams and Wilkins, 1996:397-452.

5. Craig WA, Gudnundsson S. Postantibiotic effect. In: Lorain V, ed. usually a proton pump inhibitor or some other drug, eg, bismuth, that may have intrinsic antibacterial activity, together with antibiotics. It may, therefore, be difficult to interpret the results of susceptibility testing with any single drug. It is not easy to predict in the laboratory what will happen when using combinations of drugs. Combinations can be synergistic or additive, or sometimes antagonistic.

Laboratory testing to determine the effects of combinations is very laborious and is not routinely available. Timekill and checkerboard studies can be done to assess the effect of combinations of drugs, and have been done for $\mathrm{H}$ pylori $(16,17)$. For time-kill studies, the organism is incubated with antimicrobial agents in combination (usually selecting one agent at a fraction of its MIC) and samples removed at regular intervals to determine whether the organism has been killed (18). Synergy can be derived mathematically. With the checkerboard method, various concentrations of the two drugs are tested and growth observed. If growth is inhibited better by the combination than by the single drug, the combination is said to be synergistic.

For certain bacteria with a known mechanism of resistance, it can be quicker and more reliable to detect the enzyme or the gene encoding for resistance than to determine the MIC of the organism. For Neisseria gonorrhea, a quick colorimetric test on the colony can detect the presence of the beta-lactamase enzyme that predicts for resistance to penicillin. Routinely, isolates of $S$ aureus that grow on an oxacillin screen plate can be screened for the mec gene that encodes for resistance to methicillin, rather than determining whether the isolate is resistant to oxacillin by an MIC method. Similar methods that detect resistance mutations to clarithromycin in H pylori are being developed (19).

With meticulous attention to methodology, it is feasible for the microbiology laboratory to produce reliable, reproducible and accurate susceptibility testing results for $\mathrm{H} p y$ lori. But there are limitations in applying a relatively simple laboratory assay to predict the consequence of the complex interaction of antibiotics, other drugs, the host immune response and the microorganism in any individual with $\mathrm{H} p y$ lori infection.
Antibiotics in Laboratory Medicine, 4th edn. Baltimore: Williams and Wilkins, 1996:296-329.

6. Performace Standards for Antimicrobial Susceptibility Testing. Supplement M100-S9. Wayne: National Committee for Clinical Laboratory Standards, 1999.

7. Megraud F, Trimoulet P, Lamouliatte H, Boyanova L. Bactericidal effect of amoxicillin on Helicobacter pylori in an in vitro model using epithelial cells. Antimicrob Agents Chemother 1991;35:869-72.

8. Chaves S, Gadanho M, Tenreiro R, Cabrita J. Assessment of metronidazole susceptibility in Helicobacter pylori: statistical validation and error rate analysis of breakpoints determined by the disk diffusion test. J Clin Microbiol 1999;37:1628-31.

9. Dore MP, Osato MS, Kwon DH, Graham DY, el-Zaatari FA. Demonstration of unexpected antibiotic resistance of genotypically identical Helicobacter pylori isolates. Clin Infect Dis 1998;27:84-9.

10. Hassan IJ, Stark RM, Greenman J, Millar MR. Activities of betalactams and macrolides against Helicobacter pylori. Antimicrob Agents Chemother 1999;43:1387-92.

11. Taylor KJ, Edwards-Jones V, Armitage M. Metronidazole sensitivity 
testing of Helicobacter pylori: the importance of media. Br J Biomed Sci 1998;55:118-22.

12. Hartzen SH, Andersen LP, Bremmelgaard A, et al. Antimicrobial susceptibility testing of 230 Helicobacter pylori strains: importance of medium, inoculum, and incubation time. Antimicrob Agents Chemother 1997;41:2634-9.

13. Taylor DE, Jiang Q, Fedorak RN. Antibiotic susceptibilities of Helicobacter pylori strains isolated in the Province of Alberta. Can J Gastroenterol 1998;12:295-8.

14. Johnson CC. In vitro testing: correlations of bacterial susceptibility, body fluid levels, and effectiveness of antibacterial therapy. In: Lorain V, ed. Antibiotics in Laboratory Medicine, 4th edn. Baltimore: Williams and Wilkins, 1996:813-34.

15. Megraud F. Antibiotic resistance in Helicobacter pylori infection. Br Med Bull 1998;54:207-16.
16. Coudron PE, Stratton CW. Use of time-kill methodology to assess antimicrobial combinations against metronidazole-susceptible and metronidazole-resistant strains of Helicobacter pylori. Antimicrob Agents Chemother 1995;39:2641-4.

17. Meyer JM, Ryu S, Pendland SL, Danziger LH. In vitro synergy testing of clarithromycin and 14-hydroxyclarithromycin with amoxicillin or bismuth subsalicylate against Helicobacter pylori. Antimicrob Agents Chemother 1997;41:1607-8.

18. Eliopoulos GM, Loellering RC. Antimicrobial combinations. In: Lorain V, ed. Antibiotics in Laboratory Medicine, 4th edn. Baltimore: Williams and Wilkins, 1996:330-96.

19. Marais A, Monteiro L, Occhialini A, Pina M, Lamouliatte H, Megraud F. Direct detection of Helicobacter pylori resistance to macrolides by a polymerase chain reaction/DNA enzyme immunoassay in gastric biopsy specimens. Gut 1999;44:463-7. 


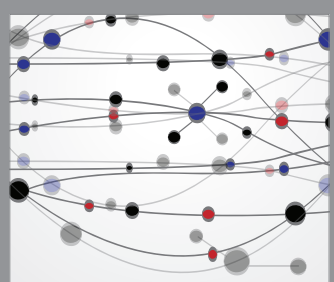

The Scientific World Journal
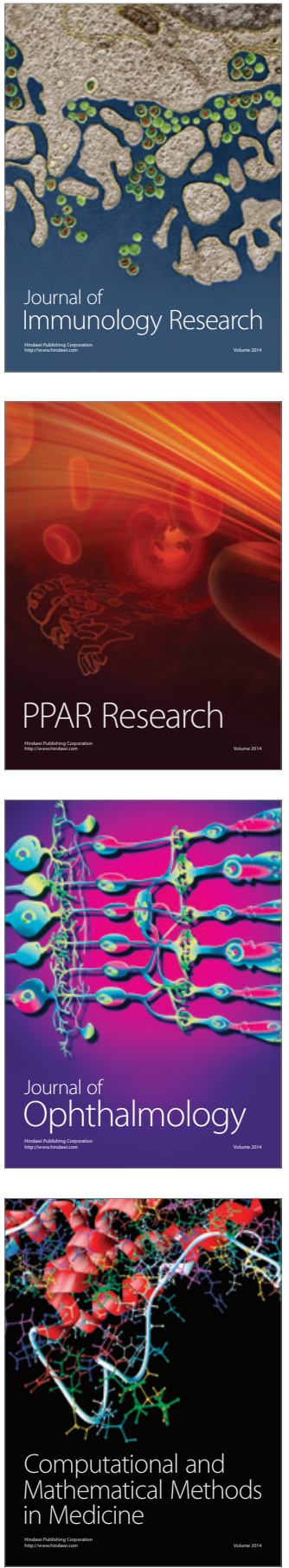

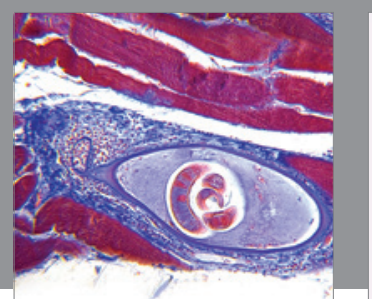

Gastroenterology Research and Practice

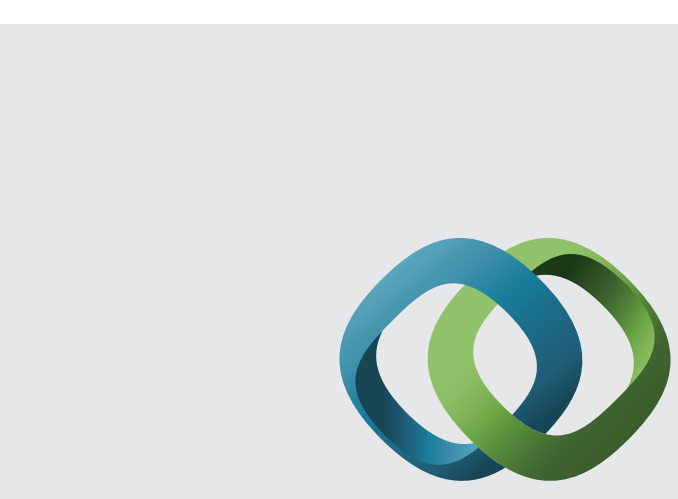

\section{Hindawi}

Submit your manuscripts at

http://www.hindawi.com
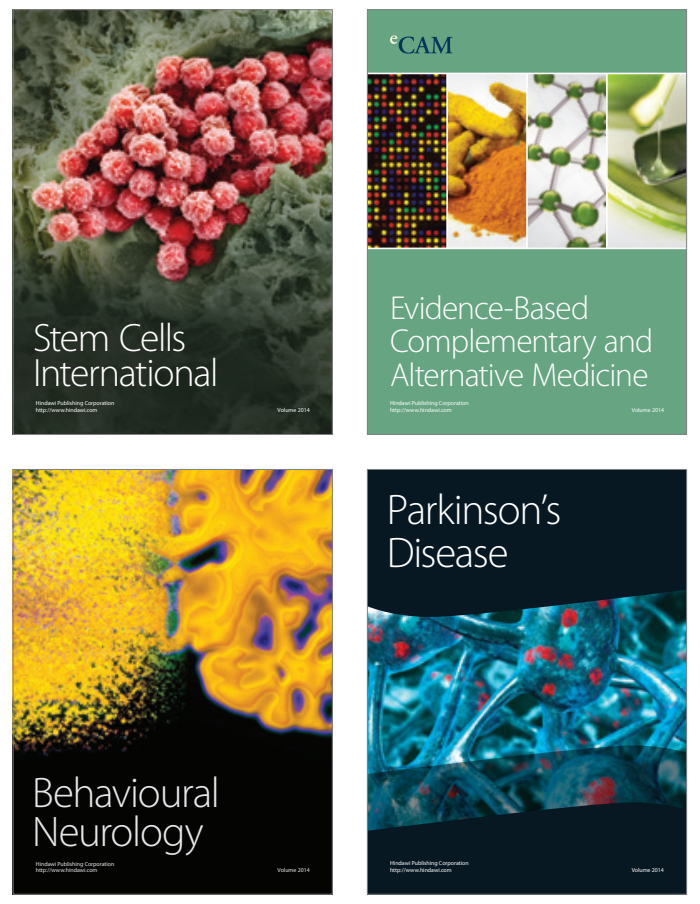
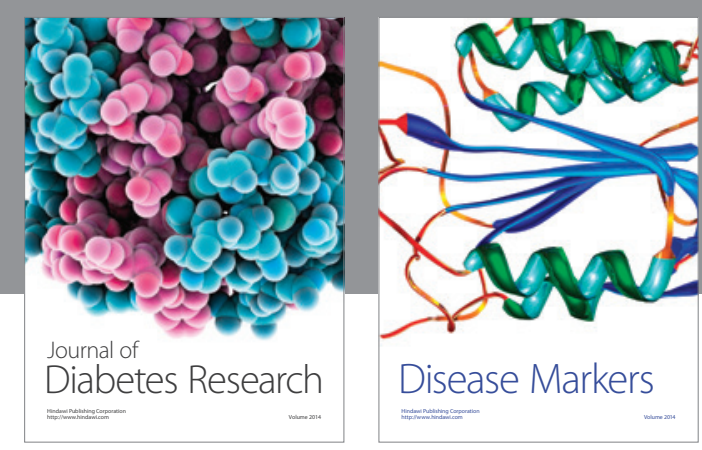

Disease Markers
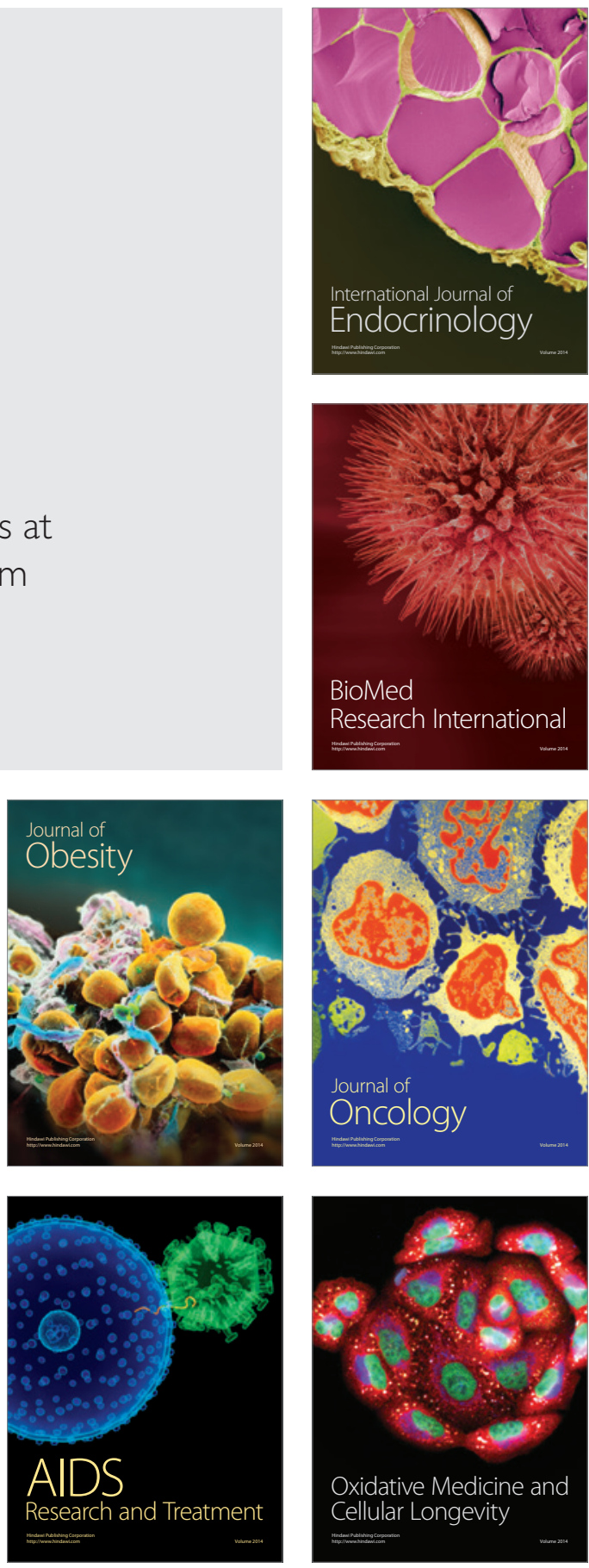